\title{
Locus of Control and Learning to Cooperate in Prisoner's Dillemma game
}

Citation for published version (APA):

Boone, C. A. J. J., de Brabander, B., van Olffen, W., van Witteloostuijn, A., de Jong, G., \& Carree, M. A. (2002). Locus of Control and Learning to Cooperate in Prisoner's Dillemma game. Personality and Individual Differences, 32(5), 929-946. https://doi.org/10.1016/S0191-8869(01)00100-3

Document status and date:

Published: 01/01/2002

DOI:

10.1016/S0191-8869(01)00100-3

Document Version:

Publisher's PDF, also known as Version of record

\section{Please check the document version of this publication:}

- A submitted manuscript is the version of the article upon submission and before peer-review. There can be important differences between the submitted version and the official published version of record.

People interested in the research are advised to contact the author for the final version of the publication, or visit the DOI to the publisher's website.

- The final author version and the galley proof are versions of the publication after peer review.

- The final published version features the final layout of the paper including the volume, issue and page numbers.

Link to publication

\footnotetext{
General rights rights.

- You may freely distribute the URL identifying the publication in the public portal. please follow below link for the End User Agreement:

www.umlib.nl/taverne-license

Take down policy

If you believe that this document breaches copyright please contact us at:

repository@maastrichtuniversity.nl

providing details and we will investigate your claim.
}

Copyright and moral rights for the publications made accessible in the public portal are retained by the authors and/or other copyright owners and it is a condition of accessing publications that users recognise and abide by the legal requirements associated with these

- Users may download and print one copy of any publication from the public portal for the purpose of private study or research.

- You may not further distribute the material or use it for any profit-making activity or commercial gain

If the publication is distributed under the terms of Article $25 \mathrm{fa}$ of the Dutch Copyright Act, indicated by the "Taverne" license above, 


\title{
Locus of control and learning to cooperate in a prisoner's dilemma game
}

\author{
Christophe Boone ${ }^{\mathrm{a}, *}$, Bert De Brabander ${ }^{\mathrm{b}}$, Martin Carree ${ }^{\mathrm{a}}$, Gjalt de Jong ${ }^{\mathrm{c}}$, \\ Woody van Olffen ${ }^{\mathrm{a}}$, Arjen van Witteloostuijn ${ }^{\mathrm{d}}$ \\ ${ }^{a}$ Faculty of Economics and Business Administration, Maastricht University, Organisation Studies Group, \\ PO Box 616, 6200 MD Maastricht, The Netherlands \\ ${ }^{\mathrm{b}}$ Faculty of Applied Economics, University of Antwerp, Middelheimlaan 1, 2020 Antwerp, Belgium \\ 'PriceWaterhouse Coopers, Archimedeslaan 21, 3584BA Utrecht, The Netherlands \\ ${ }^{\mathrm{d}}$ Faculty of Economics, University of Groningen, Postbus 800, 9700 AV, Groningen, The Netherlands
}

Received 22 September 2000; received in revised form 25 April 2001

\begin{abstract}
Boone et al. (Boone, C., De Brabander, B., \& van Witteloostuijn, A. (1999a). Locus of control and strategic behaviour in a prisoner's dilemma game. Personality and Individual Differences, 27, 695-706; Boone, C., De Brabander, B., \& van Witteloostuijn, A. (1999b). The impact of personality on behaviour in five Prisoner's Dilemma games, Journal of Economic Psychology, 20, 343-377) showed that subjects with an internal locus of control were, on average, more cooperative in a prisoner's dilemma (PD) game than subjects with an external locus of control. They conjectured that this finding should not be interpreted as evidence for stable differences in cooperative behaviour between internals and externals. Specifically, they suggested that it is the capacity to adapt to different circumstances over time that distinguishes internals from externals. In the present study we want to investigate the validity of this proposition. We argue that in a PD setting individuals gradually learn to understand the subtle interplay between cooperation and selfinterest. Repetition and learning breed cooperation because people learn to understand that cooperation is instrumental in obtaining long-run profit. There is, however, good reason to believe that individuals differ as to the speed of learning to cooperate. We hypothesise that internals are more astute in learning to cooperate in a PD game because they are more endowed with the cognitive faculties necessary for quick learning than externals. Our empirical findings indeed reveal that externals play less cooperatively, on average, in the first part of a series of PD games. However, this difference gradually
\end{abstract}

* Corresponding author. Tel.: + 31-43-3883806; fax: + 31-43-3884877.

E-mail address: c.boone@mw.unimaas.nl (C. Boone). 
disappears. In fact, the experiment suggests that learning and repetition reduce the impact of individual differences. By way of appraisal, implications for further research are discussed. (C) 2002 Elsevier Science Ltd. All rights reserved.

Keywords: Locus of control; Prisoner's dilemma; Learning; Cooperation

\section{Introduction}

Understanding the determinants of cooperative behaviour has been an important issue on the agenda of many social scientists for several decades. This is witnessed by the huge body of early experimental research in both economics and social psychology (Dawes, 1980; Pruitt \& Kimmel, 1977; Rapoport, Guyer, \& Gordon, 1976). In this research tradition, mixed-motive games, such as the prisoner's dilemma (PD), have been extensively used to model competitive versus cooperative behaviour (Raiffa, 1982). The two-party version is the most widely used class of PD games (Cox, Lobel, \& McLeod, 1991; Pruitt \& Kimmel, 1977). This setup will be used in the present study, too. Technical details of the PD are discussed at length elsewhere (e.g. Rasmusen, 1990). It suffices to mention here that the dilemma resides in the fact that the best possible outcome for all parties as a group results when each party refrains from trying to maximise her or his self-interest. However, no matter what the other party does, a player can always increase her or his payoff in the short run by defecting unilaterally. Thus, it is to each individual's advantage to defect, at least in the short run. Of course, when one of the parties defects, trust is undermined and cooperation generally breaks down. The final result is that when parties cannot resist the temptation to defect, both parties end up being worse off. It is this continuous tension between the long-run gains of cooperation versus the short-term incentives to compete which makes the game a realistic simulation of real-world phenomena, and therefore interesting to study (Rasmusen, 1990).

Most experiments in the past have studied the impact of situational determinants on cooperation. In this respect, an interesting stylised fact is that subjects, at least from Western societies, tend to prefer the competitive strategy when playing one-shot PD games. However, when individuals play several games in a row against the same party, astute subjects quickly learn to cooperate and often enter into tacit collusion (Raiffa, 1982). This is the case irrespective of whether or not the repeated games have a finite (known) or infinite (unknown) horizon. Individuals gradually learn to develop long-term thinking in these games, because they recognise their mutual dependency in obtaining a reasonable payoff (Pruitt \& Kimmel, 1977). So, repetition and learning breed cooperation.

Whereas previous research almost exclusively focused on identifying the circumstances triggering cooperative behaviour, the question whether and why individuals differ with respect to cooperative behaviour received only scant attention. This is somewhat surprising as Kuhlmann and Marshello (1975), already 25 years ago, demonstrated that individuals have different tendencies to compete or cooperate in mixed-motive games, where these tendencies, or orientations, are relatively stable. Because we agree with Pruitt and Kimmel (1977), we followed their plea to study the impact of individual attitudes and personality traits on cooperation in mixed-motive games. Specifically, we started a series of experiments with the purpose of investigating the behavioural implications of specific personality traits in a PD setting. We chose to focus on locus of control in the current paper because it is a fundamental personality trait, which has been 
shown to have important ramifications for behaviour in a social dilemma setting (Boone, De Brabander, \& van Witteloostuijn, 1999a, 1999b). Before summarising the major findings of our previous work, recall that the locus of control construct refers to individual differences in a generalised belief in internal versus external control of reinforcements (Rotter, 1966). Those who believe in external control (i.e. externals) see themselves as relatively passive agents and believe that the events in their lives are due to uncontrollable forces. Externals consider what they want to achieve as dependent upon luck, chance and powerful persons or institutions. They think that the probability of being able to control their lives by their own actions and efforts is low. Conversely, those who believe in internal control (i.e. internals) see themselves as active agents, feel that they are masters of their fates and trust in their capacity to influence their environment. Internals believe that they control the events in their lives by their own effort and skill.

In a previous experiment we found that, on average, internals played significantly more cooperatively than externals in a repeated PD game (Boone et al., 1999a, 1999b). The findings also made clear that this difference was not the result of internals being more altruistic, but rather of their tendency to use behaviour strategically in order to control their environment to obtain valued outcomes. In other words, internals play more cooperatively, on average, in a PD because it furthers their self-interest. In fact, they readily switch to a competitive strategy when this is more appropriate to obtain a higher payoff.

At a more general level, the results of the experiment made two things clear. First, it is essential to study cooperative behaviour dynamically because individuals do not necessarily make an either/or choice between cooperation and competition, as is often implied in a static analysis. As a result, static analyses of cooperative behaviour largely miss the mark. Second, we also concluded that the same comment can be made concerning the behavioural consequences of differences in locus of control. Specifically, the findings underscored the suspicion that what distinguishes internals from externals is not so much average and stable differences in behaviour, but rather the capacity to adapt to different circumstances over time. Again, searching for differences at a specific point in time might be misleading. If we do not understand the overall pattern and meaning of behaviour, analysing cross-sectional slices of that behaviour does not allow us to draw unambiguous conclusions concerning the importance of individual differences.

In the present study we want to explore and combine the consequences of both of these insights further. We argue that people from Western cultures, in which opportunism is deeply rooted (Boone \& van Witteloostuijn, 1999), have to learn to cooperate in a PD game. They have to understand that in the long run cooperation is in their self-interest. There is, however, good reason to believe that individuals differ as to the speed of learning to cooperate. It is here that locus of control enters the picture. We hypothesise that internals are more astute in learning to cooperate in a PD game. This proposition follows logically from the very definition of the concept. Internals, who believe in their own potency to master their environment, are much more likely than externals to use all their faculties to understand and influence their surrounding world as this heightens the probability of successfully regulating behaviour (Boone, 1992; Lefcourt, 1982; van Olffen, 1999). Internals will question their assumptions more and will be more attentive to cues and feedback relevant to their decision making because they believe this may improve their performance. To test the validity of these general behavioural consequences of the locus of control construct, numerous experiments were conducted to relate locus of control with cognitive activities like attention and alertness, and information search and assimilation. Reviewing this 
literature, Phares (1976, p. 78) concludes that internals "acquire more information, make more attempts at acquiring it, are better at retaining it, are less satisfied with the amount of information they possess, are better at utilising information and devising rules to process it and generally pay more attention to relevant cues in the situation." All this provides strong support for the validity of the locus of control construct as it is indicative of a basic striving of internal individuals to actively engage in the seeking for relevant cues in their environment to determine and make sense out of their position and to guide or adapt their behaviour accordingly.

In the context of a PD game we expect that this eagerness of internals to learn how the world works, makes them more alert and sensitive to the subtle interdependency of payoffs and the long-run instrumentality of cooperation to obtain valued outcomes for one-self. However, we think that externals will eventually catch up and change their strategy from competition to cooperation, too. This is because (1) cooperation enhances self-interest and (2) it has been shown that externals are not less intelligent than internals (Lefcourt, 1982). We assert that externals just learn slower than internals because they are less endowed with the cognitive faculties that sustain quick learning, as described earlier. To summarise, we expect that the finding of our previous experiment - internals behave more cooperatively than externals, on average - will only show up in the first part of a series of PD games, but will subsequently disappear. In the long run, that is, when everybody learned and internalised the rules of the game, individual differences with respect to locus of control become irrelevant.

\section{Method}

\subsection{Games}

Because the experiment aims at extending insights from previous work, the games and procedures we used in the present study are very similar to those in Boone et al. (1999a, 1999b). The experiment was conducted during a 4-week course on statistical methods for second-year students of management and organisation at the Dutch University of Groningen. The 4-week course was part of a new curriculum, and only those students who had passed the first-year program were allowed to participate. At the onset of the experiment students filled out a (computerised) questionnaire, revealing background and personality information. The actual experiment consisted of two parts. In the first week of the course 182 students played five different PD games in a row (Experiment I). To evaluate whether long-run learning actually takes place, 92 of these 182 students volunteered to play the five PD games again 8 days later (Experiment II).

It is important to stress that these 92 subjects were not a random sample of the 182 who started the course and participated in Experiment I. Instead, they re-participated on a voluntary basis, provided they had fulfilled some mild, formal criteria concerning attendance in the course. Fortunately, analyses show that this group of students does not significantly differ from the "dropout" subjects with respect to locus of control, gender, age and average cooperative behaviour in the five games of Experiment I, suggesting that attrition did not cause a problem of sample selection bias in Experiment II. To be sure, however, that systematic sample differences do not 
account for our findings, we will not only analyse the data of Experiment I for the original sample of 182 subjects, but also for the subset of 92 subjects that also participated in Experiment II.

Concerning the purpose of the experiment, we only announced that it was designed to deepen their and our understanding of behaviour in a game-theoretic setting. The students were promised feedback on the major findings of the research project after completion of the 4-week course. We also guaranteed strict confidentiality of the information provided by the questionnaires.

In both experiments, five PDs were presented to the subjects in a fixed order, mainly for the sake of simplicity and comparability of findings between the experiments. The order of presentation and the main characteristics of the games are summarised in Table 1. We acknowledge that choosing this fixed-order design has also a drawback. Specifically, increases in the average level of cooperation across the games within Experiments I and II, respectively, cannot be unambiguously ascribed to learning, but could also be the result of the different game conditions. However, in this particular study, we think that the fixed-order presentation is not problematic for two reasons. First, because the games were presented in the same fixed order in both Experiments, our design eases comparison of findings between Experiments I and II. This is important because we are interested in finding out whether "true" learning takes place over longer periods of time. Note that any systematic difference in average cooperative behaviour between Experiments I and II cannot be explained away by the fixed-order presentation of the games. Second, the focus of the present study is on detecting individual differences in the dynamics of cooperation over time and across different situations. The fixed-order design in no way precludes drawing conclusions as far as this research issue is concerned.

Each game consists of 12 rounds of choices, except for game III in both experiments. In fact, game III has an unknown horizon, being ended at random after 13 rounds in Experiment I and after nine rounds in Experiment II. In the first two games, subjects played against a fictitious party, receiving no information on the choices made by that party in each round. Therefore, these games are essentially "one-shot" or non-interactive games. In the last three games, dyads were randomly formed, and the subjects played interactive repeated games. That is, choices were made

Table 1

Main characteristics of experimental games

\begin{tabular}{lll}
\hline Game & Type of game & Main characteristics of game \\
\hline I & "One-shot" & $\begin{array}{l}12 \text { choices (low or high price) against fictitious party } \\
\text { No information on past behaviour of other party } \\
\text { Baseline game }\end{array}$ \\
& "One-shot" & $\begin{array}{l}12 \text { choices (low or high price) against fictitious party } \\
\text { Information on past behaviour of other party }\end{array}$ \\
II & Repeated & Subjects make independent and simultaneous choices in each round \\
& & Exchange of choices made by both parties after each round \\
& Unknown horizon ("infinite" game) & Final payoff equals sum of payoff in each round \\
IV & Repeated & Same as game III, except horizon which is finite and known (12 rounds) \\
V & Repeated & Same as game IV, except payoff matrix which is changed to elicit cooperation \\
\hline
\end{tabular}


simultaneously and independently in each round, after which subjects were informed of the choice made by the other party. Game III has a so-called infinite horizon as the subjects were not informed about the game's end round (i.e. game III was ended at random). The fourth game is similar to game III except that we now announced in advance that the game would end in round 12. In the last game, we changed the values of the payoff matrix used in all the other games such that the incentive to cooperate might increase in the eyes of the players. The horizon of game $\mathrm{V}$ was, again, finite and known to be 12 rounds. The instructions and payoff matrices of the games can be found in the Appendix. The games in both experiments are close copies. Only slight differences in the payoff structure (without affecting the games' formal Nash equilibrium outcomes) were introduced so as to trigger the students' alertness.

Note that the first two non-interactive games can be considered as baseline measures of cooperative behaviour. Both measures give an impression of the subjects' basic inclination to pursue a competitive or cooperative strategy. The bulk of experimental research has revealed that competitive strategies are preferred in such "one-shot"- settings, at least in nations with an individualistic cultural tradition (Boone \& van Witteloostuijn, 1999). The baseline strategy, however, also depends on the players' educational background: economics students, for instance, tend to compete much more often than their colleagues studying other majors (Frank, Gilovich, \& Regan, 1993). In the second game, we manipulated the reputation of the other (fictitious) party by suggesting that this party was trustworthy because (s)he had made cooperative choices in each of the 12 rounds in the previous encounter (i.e. cooperative feedback). We expect baseline cooperation to drop because, as we argued elsewhere, opportunism is deeply rooted in Western societies. Indeed, the individualistically oriented Dutch subjects in a previous experiment were inclined to "exploit" the "sucker" with a cooperative reputation by reducing the number of cooperative choices almost to zero (Boone \& van Witteloostuijn, 1999). Subsequently, we expect cooperation to gain importance gradually, on average, in the last three repeated games. As said before, when players are engaged in repeated interaction with another party they quickly learn to cooperate, and often enter into tacit collusion, irrespective of whether the game's horizon is known or not (Raiffa, 1982).

\subsection{Experimental procedure}

Experiments I and II took place in one large room. The procedure used in both experiments was the same. In the room there were three groups; each group had three rows of pairs of tables. The pairs of tables were separated by the space of one table. When entering the room, the students were randomly distributed over the three groups and within the three groups over the available seats. Pairs of subjects were formed to play the repeated PD games (i.e. the last three games in Experiments I and II). These dyads consisted of students sitting side-by-side. Note that the purpose of this 2-fold randomisation procedure was to avoid the occurrence of the same random dyads in both experiments as much as possible. We deemed it important to have different dyads in both experiments in order to find out whether learning takes place irrespective of the partner with whom a subject is playing. It is, for instance, possible that a subject plays more cooperatively in a second encounter when she knows her opponent from a previous encounter. We trusted that simple randomisation concerning the second pairing would make the occurrence of the same pairs rare. Therefore, we did not randomise with the constraint that no one would 
have the same partner as in Experiment I. Unfortunately, the randomisation procedure without constraint resulted in the extremely unlikely outcome of 10 pairs of subjects in Experiment II who also played against each other in Experiment I. To check whether this constitutes a problem for the results reported below, we redid the analyses related to Experiment II without these 20 subjects. These findings, however, are very similar compared with those pertaining to the 92 subjects. Note also that the average level of cooperative behaviour in each of the five games of Experiment II of the subjects who played twice against the same partner $(n=20)$ does not significantly differ from the cooperative behaviour of the subjects who played against a new partner $(n=72)$. To summarise, both checks make clear that the relative "failure" with respect to making new random pairs does not influence the outcomes and interpretations of the analyses reported below.

One experimenter and two assistants, identified by wearing similar shirts, guided each of the three groups. The assistants handed out the various forms with information while the experimenter remained in front of the group during the entire experiment. All groups started the experiment at the same clock time.

The PD was presented as an oligopoly pricing problem. The experimenter first announced that five games were to be played, and that detailed information about each game would be provided just before the game involved started. Then, he showed and explained the general payoff structure of the first game (see the Appendix). The subjects could make two choices: setting a low price (corresponding with a competitive choice) or setting a high price (corresponding with a cooperative choice). The instructional phase fully and redundantly explained the interdependent nature of the payoffs, so that the consequences of different combinations of choices were clearly understood (see also Frank et al., 1993). Following Schlenker, Helm and Tedeschi, (1973), we avoided the use of such terms as "compete", "cooperate", "defect" and "sucker" so as to insure a neutral instructional set. Note that in the remainder of this paper we use different terms ranging from less to more neutral to denote "the other party" in the game. We stress, however, that we only used neutral terms in addressing the participants during the experiments.

The experimenter, who gave instructions as to when and how to make choices in each game, strictly controlled the pace of the experiment. The subjects received a booklet with the instructions of each game and a corresponding response sheet. The experimenter, using slides, clarified every instruction. As mentioned earlier, games I and II involved making 12 choices in a row against a fictitious party. At the onset of game III, the experimenter announced each subject's opponent/partner for the three repeated games. The subjects received a booklet with small blank notes and were instructed in each round to make a choice independently and simultaneously. Next, subjects had to write down their choice on such a blank note. After every subject had written down her or his choice, the experimenter instructed the parties to exchange the notes with their choice. Following this exchange, subjects marked their choice, the opponent's choice and their payoff on a response sheet. This procedure was repeated for each round in the three interactive games. Of course, apart from the exchange of notes no communication was allowed.

Following standard experimental gaming, the subjects were instructed to maximise their payoff during the experiment (Pruitt \& Kimmel, 1977; Schlenker et al., 1973). Additionally, although much experimental psychology has revealed that subjects take experiments very seriously anyway, we introduced an extra motivational incentive by means of the announcement that the top-five players in terms of the accumulated payoff would receive a token for music 
records. We also appealed to the social motivation for prestige by telling the subjects that the ranking of payoffs, including the players' names, would be announced in public in a final plenary session at the end of the 4-week course, on a bulletin board and on the Faculty's students' internet homepages.

\subsection{Subjects and measures}

The study pertains to 182 students of management and organisation of the University of Groningen for Experiment I, and a subset of 92 of these subjects for Experiment II. The information and descriptives reported in this section pertain to the sample of 182 students. The average age of the subjects is 19.65 years (S.D. $=1.04)$, and the majority of the participants were male $(66 \%)$.

Their locus of control scores were measured with the well-known and widely used Rotter scale (Rotter, 1966), translated into Dutch by the authors. The original scale contains 29 forced-choice items, 23 of those items being designed to measure the locus of control expectancies (and six being filler items). Each item consists of a pair of statements. The respondents have to choose between an "internal" and an "external" alternative. The following pair of statements is a clear example: "Many times I feel that I have little influence over the things that happen to me" (external alternative) and "It is impossible for me to believe that chance or luck plays an important role in my life" (internal alternative). A total locus of control score is obtained by counting the number of external alternatives chosen (with minimum zero and maximum 23). The number of filler items in the present study was increased to 14 in order to make the purpose of the test more obscure. The reliability of our Dutch translation was demonstrated in several studies (Boone, 1992; Boone, Gerits, \& Willemé, 1990; De Brabander, Boone, Gerits, 1992). Cronbach's alpha (Cronbach, 1951) amounts to 0.65 ( $n=182$ with 23 items) in this sample, which concurs with the internal consistencies reported by Robinson and Shaver (1973) and Rotter. The value of alpha calculated for this sample is well above the lower limits of acceptability, generally considered to be in the $0.50-0.60$ range (Nunnally, 1978). The average Rotter score of the present subjects equals 11.51 (S.D. =3.37), which is in line with averages reported for other samples of similar subjects (Boone et al., 1999b).

Following other researchers (Cox et al., 1991; Uejio \& Wrightsman, 1967), we measured cooperative behaviour by counting the total number of cooperative choices in each game. Recall that in game III 13 and nine rounds were played in Experiments I and II, respectively. In order to standardise measures over the five games, we multiplied the total number of cooperative choices in game III with the ratio 12/13 in Experiment I and 12/9 in Experiment II.

In the analyses presented later we treat gender as a covariate because females appear to have a more external perception of control than males [average score equals 11.10 for males (S.D. $=3.41)$ and 12.31 for females (S.D. $=3.15) ; F$-value $=5.37$ and $P=0.022]$. This is consistent with several previous findings (McGinnies, Nordholm, Ward, \& Bhanthumnavin, 1974; De Brabander and Boone, 1990). A probable cause of this difference is suggested by McGinnies et al. (p. 454) by indicating that "[t]here are, in all probability, few countries where women have achieved equality of opportunity with males and where they possess freedom of self-determination to the same extent as males. In any case, the present females probably were reporting a perception of their status which was matched, at least for them, by social reality." Descriptives of the variables under study are presented in Table 2 . 
Table 2

Descriptives

\begin{tabular}{lrrrr}
\hline Variables $^{\mathrm{a}}$ & Mean & S.D. & Minimum & Maximum \\
\hline Locus of control & 11.51 & 3.37 & 4 & 21 \\
Age & 19.65 & 1.04 & 18 & 26 \\
Male (0)-Female (1) & 0.34 & 0.22 & 0 & 1 \\
& & & & \\
Experiment I & & 3.61 & 0 & 12 \\
Cooperation game I & 5.74 & 4.09 & 0 & 12 \\
Cooperation game II & 4.50 & 3.14 & 0 & 12 \\
Cooperation game III & 4.91 & 3.96 & 0 & 12 \\
Cooperation game IV & 5.36 & 3.91 & 0 & \\
Cooperation game V & 6.91 & & & 12 \\
& & 4.64 & 0 & 12 \\
Experiment II & & 4.67 & 0 & 12 \\
Cooperation game I & 6.53 & 4.19 & 0 & 12 \\
Cooperation game II & 5.18 & 4.17 & 0 & 12 \\
Cooperation game III & 8.61 & 4.17 & 0 & \\
Cooperation game IV & 8.39 & & & \\
Cooperation game V & 8.13 & & & \\
\hline
\end{tabular}

a $n=182$ except for Experiment II, where $n=92$.

\section{Results}

Before analysing the effects of locus of control on cooperative behaviour, a few general remarks with respect to the descriptives reported in Table 2 are worth making. First, the relatively high average number of cooperative choices made in baseline game I (5.74 and 6.53 in Experiments I and II, respectively) suggests that the present subjects have a more cooperative inclination than the students in a previous experiment [compare with Boone et al. (1999b), where this average equalled 2.0]. A possible reason for this difference may be that the subjects in the current sample are management and organisation students, and not economics students as before. As already mentioned above, Frank et al. (1993) showed that exposure to the self-interest model commonly used in economics alters the extent to which people behave in self-interested ways. It is very likely that management and organisation students are less exposed to this "hard core" economics paradigm and more to "softer" business courses with a psychological and/or sociological flavour (e.g. organisational behaviour) than economics majors. This is immediately clear from a comparison of the curricula of both study programs, revealing a much smaller proportion of "hard" economics courses in the management and organisation curriculum. In this respect, we showed elsewhere that even among economics students, the likelihood of cooperation increases with the number of courses students have followed in which cooperation is emphasised (Boone \& van Witteloostuijn, 1999).

Note also that the number of cooperative choices drops in game II in Experiment I (from 5.74 to 4.50 ) and II (from 6.53 to 5.18), as expected. Paired $t$-tests show that this decrease in cooperation is significant $(t=3.59$ and $P=0.000$ in Experiment $\mathrm{I}$, and $t=2.85$ and $P=0.003$ in Experiment II). Apparently, opportunism is triggered when the other party has a cooperative 
reputation. Subsequently, the incidence of cooperation rises gradually in the last three repeated games of Experiment I, again as expected (Table 2). Interestingly, in Experiment II cooperation continues to rise in game III over and above the level of cooperation that could be observed in game $\mathrm{V}$ in Experiment I. Thus, although there is an 8-day interval between both experiments, the trend of increasing average cooperation revealed in Experiment I can simply be extrapolated to Experiment II. This indicates that true learning takes place. Finally, we observe that, overall, this general pattern of average cooperation in both experiments is very similar to the one found for another sample of subjects (Boone et al., 1999b), providing confidence in the reliability of the data.

Because Rotter scores tend to be normally distributed [a Kolmogorov-Smirnov test shows that the distribution of Rotter scores in the present sample does not significantly deviate from a normal distribution either $(z=1.05$ and $P=0.220)$ ], it is likely that the implications of behavioural differences associated with the locus of control will be most apparent at the extreme scores. For the purpose of our repeated-measures ANOVA reported below, we therefore classified the subjects in both experiments into three different phenotypic groups based on the terciles of the locusof-control scores of the 182 subjects (instead of applying the usual two-group classification based on a median split): internals, those with an intermediate Rotter score (intermediates) and externals. This results in 55 internals, 71 intermediates and externals in Experiment I. These numbers are 25, 38 and 29 in Experiment II, respectively. Fig. 1 presents the average number of cooperative choices made in each of the five PD games in Experiment I by each locus-of-control group. The results of Experiment II are shown in Fig. 2.

The data were analysed with repeated-measures ANOVAs with the number of cooperative choices in each game as the dependent variable and one within-subject factor with five levels (GAME). The between-subject factor is locus of control (LOC). Note that gender was entered in the analyses as a covariate. In Experiment I, the factor GAME has a significant effect on average cooperation $(F=2.386$, d.f. $=4$ and $P=0.050)$. Thus, the trend towards more cooperation from game II onwards is significant. This pattern does not significantly differ over the three locus-ofcontrol groups. That is, GAME $\times$ LOC is not significant $(F=0.756$, d.f. $=8$ and $P=0.756)$. The between-subject effect of LOC, however, is significant $(F=3.664$, d.f. $=2$ and $P=0.028)$. So, there are overall differences between internals, intermediates and externals concerning the extent of cooperative behaviour in Experiment I. Although GAME $\times$ LOC is not significant, Fig. 1 suggests that the differences between the three locus-of-control groups can only be observed in games II, III and IV. Separate ANOVAs per game indeed reveal significant differences in game III $(F=3.226$ and $P=0.042)$ and game IV $(F=3.637$ and $P=0.028)$ caused by external subjects being less cooperative than their internal and intermediate counterparts (post-hoc tests reveal that the differences between internals and intermediates are small and not significant). The overall ANOVA for game II, however, is not significant, although a post-hoc test indicates a marginally significant difference between externals and intermediates (mean difference $=1.41$ and $P=0.055$ ). Note that the level of cooperation of internals and intermediates rises gradually from game II onwards. This is not the case for externals. Externals only catch up with intermediates and internals in the last game when their level of cooperation increases drastically compared with game IV. As a result, there are no significant differences in game V anymore. Interestingly, in game I, the differences are not significant, suggesting that the observations mentioned above cannot be ascribed to differences in the baseline inclination to cooperate. In order to check for the 
robustness of these results we also performed non-parametric Kruskall-Wallis tests to detect differences between the locus-of-control groups. This test reveals a significant between-subject effect of LOC on the average level of cooperation of the five games (Chi-square $=6.894$, d.f. $=2$ and $P=0.032$ ). Game-by-game analysis again shows that the differences between the locus-ofcontrol groups only materialise in game III and IV (Chi-square $=7.001$, d.f. $=2$ and $P=0.030$, and Chi-square $=6.668$, d.f. $=2$ and $P=0.036$, respectively). These findings are exactly the same as the parametric analyses reported above.

In Experiment II, none of the factors is significantly related to the incidence of cooperative behaviour, except for the factor $\operatorname{GAME}(F=10.558$, d.f. $=4$ and $P=0.000)$. Apparently, the subjects average level of cooperation starts at the level where it ended in Experiment I and further increases until it reaches its equilibrium at a high average value (around 8 out of 12; see Table 2). As the subjects learned to cooperate, the effect of individual differences with respect to locus of control all vanished, as expected (this is also confirmed by Kruskall-Wallis test results). That is, from Experiment I to Experiment II, true learning has apparently taken place among all locus-ofcontrol groups.

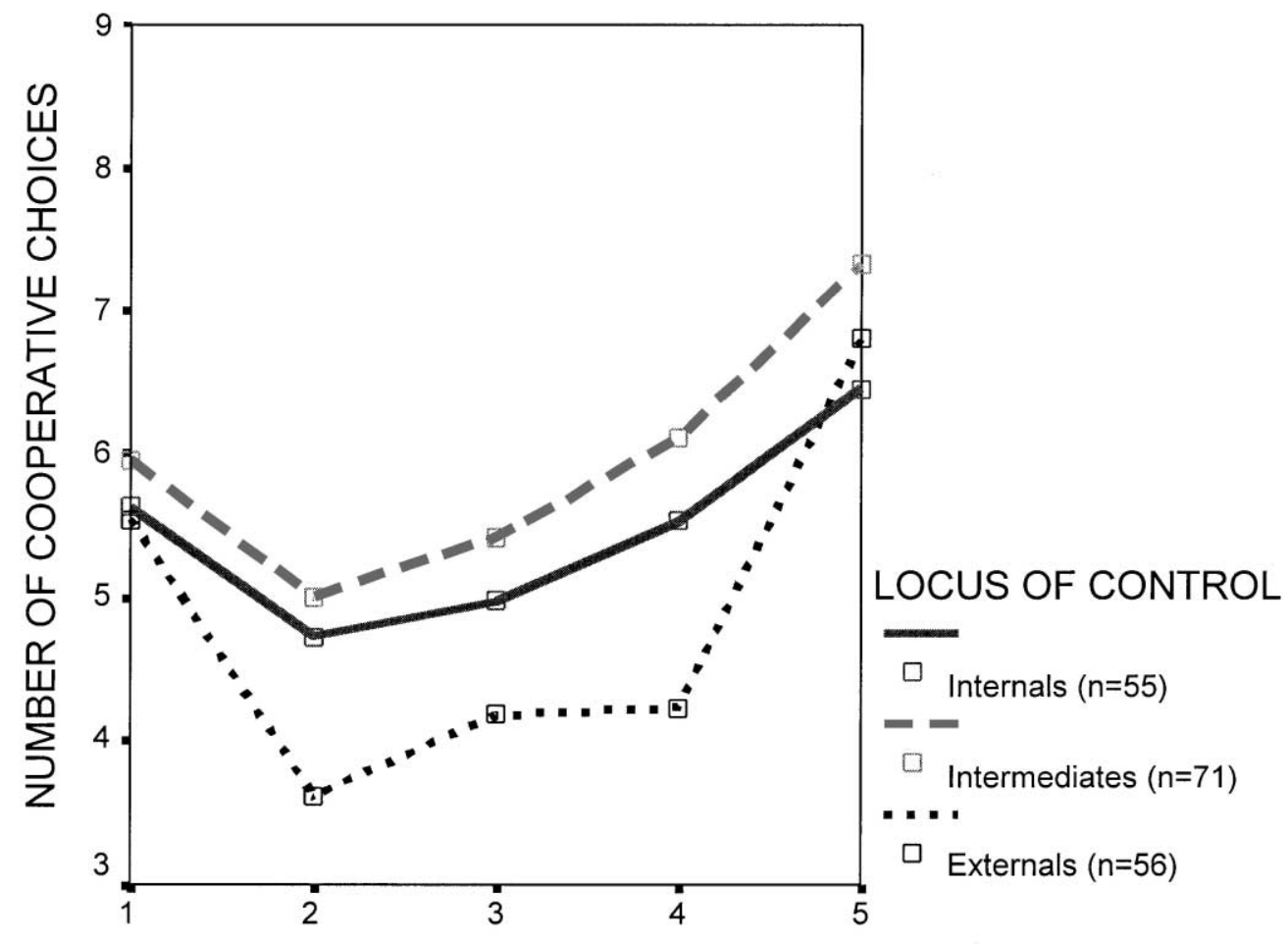

GAME

Fig. 1. Locus-of-control and number of cooperative choices (Experiment I; $n=182$ ). 
Recall that Experiment II only pertains to a subset (i.e. 92 volunteers) of the 182 subjects that participated in Experiment I. When comparing the results of both Experiments, it is therefore important to rule out the possibility that the observed convergence in cooperative behaviour among the locus-of-control groups is due to (possibly arbitrary) sample differences. For this purpose we re-analysed the data of Experiment I only for those subjects who participated in Experiment II as well. Fig. 3 shows the results of this exercise. The pattern of findings is almost identical to that pertaining to the full sample (compare Figs. 1 and 3), although the betweensubject effect of LOC is not significant anymore (ANOVA test: $F=1.913$, d.f. $=2$ and $P=0.154$; Kruskall-Wallis test: Chi-square $=3.573$, d.f. $=2$ and $P=0.168)$. The reduced significance is of course due to the $50 \%$ drop in degrees of freedom. Taken together, as this sensitivity analysis essentially yields the same qualitative results, the observed convergence between the locus-ofcontrol groups is unlikely to have been caused by subtle sample selection effects.

Finally, it should be noted that one could argue that the existence of (slightly) different conditions in Experiment I vis-à-vis Experiment II weakens the interpretation of shifts in cooperation as "pure" learning effects. Similarly, a point could be made that the evidence for externals catching up with internals and intermediates would probably be stronger if the subjects had played a number of identical procedures over time. The latter would enable one to observe

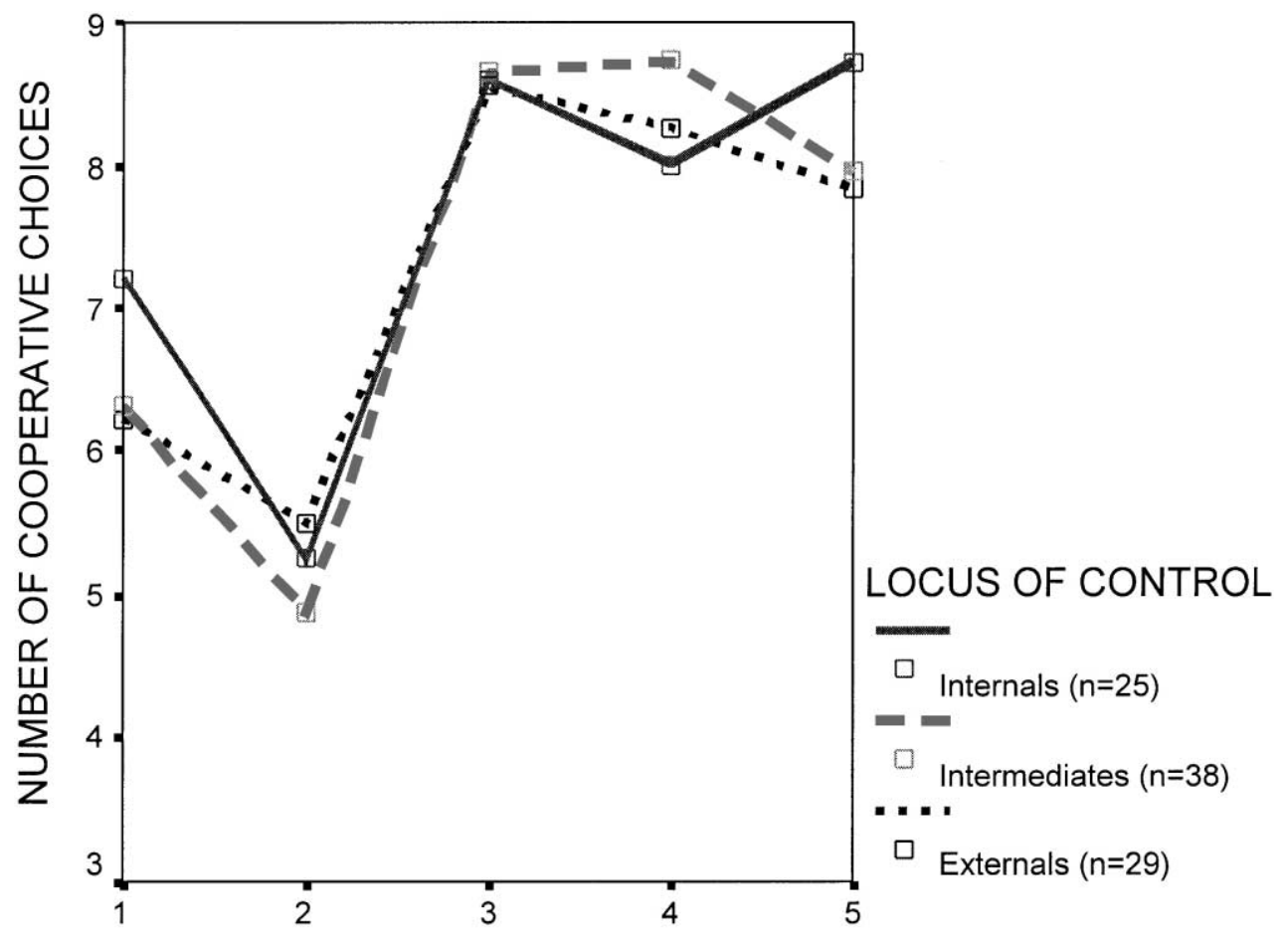

GAME

Fig. 2. Locus-of-control and number of cooperative choices (Experiment II; $n=92$ ). 
learning independently of differences in experimental conditions (these issues were already touched upon when explaining our fixed-order design approach in Section 2). Notwithstanding these qualifications, we think, however, that it is very reassuring that even in the one-shot games of Experiment II all participants, irrespective of their locus of control, "pick up" cooperation at exactly the same level they ended Experiment I. As both experiments are almost identical, we think that this finding is clear evidence of all subjects learning to play cooperative over time. In addition, presenting different game conditions to subjects has also an advantage because it broadens the range of observed behaviour. This makes sense when testing for individual differences as it allows one to assess their general impact in a broad range of circumstances.

\section{Appraisal}

The aim of the present study was to investigate the dynamic relationship between locus of control and cooperative behaviour. For this purpose, we conducted two experiments. In Experiment I, where subjects do not yet have any experience in playing PDs, we found that external subjects were significantly less cooperative, on average, than internal and intermediate subjects. However, this difference disappeared in the last game of Experiment I. Apparently, as expected,

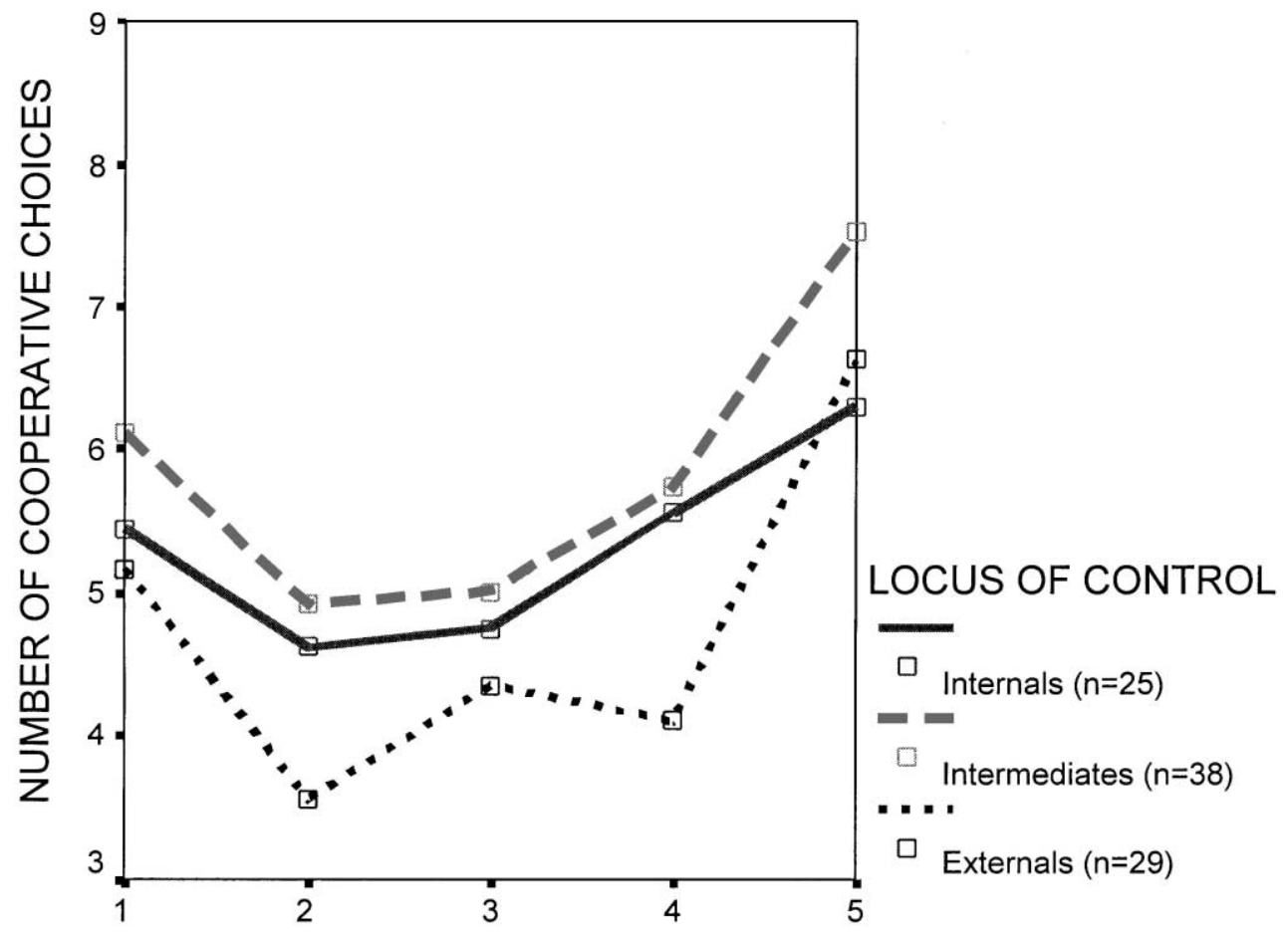

GAME

Fig. 3. Locus-of-control and number of cooperative choices (Experiment I; $n=92$ ). 
externals tend to lag behind as far as learning to cooperate is concerned, only catching up with the other groups after playing several PD games. The fact that we fail to observe significant differences between internals and intermediates came as a surprise. Perhaps, only relatively "extreme" externals suffer from symptoms of so-called learned helplessness (Lefcourt, 1982), which make them less alert and sensitive to the subtle interdependencies so dominant in a PD context. It should be stressed that these findings are probably to some extent sample specific. This is because the three locus-of-control groups were not determined by general population norms (which do not exist), but by using the observed locus-of-control scores of the subjects participating in the study. Although the mean locus-of-control score of the subjects in the present sample lies at the midpoint of the scale (i.e. 11), a sample of university students is clearly not representative of the "average" individual in society at large, but probably tends to lean toward the more internal part of the population. It is therefore conceivable that in more representative samples (i.e. more "external" samples compared with the present one) the slower learning to cooperate starts closer to the average locus-of-control score of that sample, i.e. also for "intermediates".

We argued that the underlying reason for the observed differences between the locus-of-control groups is related to differences in the capacity to learn. To be sure, only changes in actual behaviour rather than "true" learning can be observed. This is of course a major limitation of the present but also of many other studies related to learning: learning is (and in many cases can) only (be) inferred ex post. Similarly, the PD, although widely used to model competitive versus cooperative behaviour, does not, in itself, allow one to understand unambiguously the true motives or reasons of individuals to cooperate or to compete. It is a black box in which behaviour can be driven by a plethora of, not necessarily mutually exclusive, reasons and motives. Cooperation can be the result of astuteness, insight and learning, but also of interpersonal trust, the propensity to take risks, altruism, collective orientation, etc. In our view, motives such as collective orientation and altruism are unlikely candidates to explain the effect of locus of control on cooperative behaviour in Experiment I. There are two major reasons to believe that, indeed, learning to cooperate is the underlying cause.

First, and most important, is the finding that no differences between the locus-of-control groups could be observed anymore in Experiment II. In fact, cooperation was the rule rather than the exception in Experiment II. Apparently, having experience in playing the PD game is sufficient to make people cooperate, so rendering locus-of-control differences irrelevant. It is clear that if stable motives, such as altruism, would have produced the results in Experiment I, then differences in cooperative behaviour would not disappear overnight. As a result, the pattern of findings is very consistent with individuals learning that cooperation is instrumental to further their selfinterest (i.e. to obtain a reasonable payoff).

Second, there is another reason why stable motives are unlikely candidates to explain the observed effect of locus-of-control on cooperative behaviour in Experiment I. If these motives were the underlying reason to cooperate, we would expect to observe significant differences in the baseline (non-interactive) game I-measuring the basic inclination of an individual to compete or cooperate. However, we fail to do so.

Finally, a few general remarks are worth making. The present study clearly underscores the value of the claim we made earlier. It shows that cross-sectional findings are at best misleading, and that it is indeed essential to study personality and cooperation dynamically (Boone et al., 1999a). It also sheds new light on the important — but frequently neglected - difference between 
strong and weak situations with respect to the impact of personality on behaviour (Weiss \& Adler, 1984). We agree with Weiss and Adler that personality research can benefit a lot if researchers would do more than just paying lip service to the distinction of weak versus strong situations. The point is that personality can only serve as a guide in explaining behaviour when the environment is uncertain and ambiguous (i.e. weak). However, when enough cues are provided as to the type of behaviour that is appropriate - either normative or instrumental - , then individual differences are less important in understanding that behaviour. We conjecture that experience and learning may make weak situations strong, and therefore reduce the impact of personality. The present findings are consistent with this account, at least for the case of the locus-of-control trait in a dynamic setting, as they suggest that experience indeed weakens the impact of locus-of-control. Our study is only another small step into the study of the very complex area of the impact and interplay of personality and experience. Given the promising findings, however, we believe that this issue deserves more attention in future research. Specifically, replications and/or extensions using other situations and personality traits are essential in order to test the generality of our findings and interpretations.

\section{Acknowledgements}

We greatly appreciate the constructive comments of the editor and of the two anonymous reviewers. Thanks also to Tomas Klos for data input, and to Joyce Wicherts and Charlotte Rekko for data management and assistance. The research reported here is part of a larger project on learning behaviour of economic agents financed by the Netherlands' national research council (NWO), cluster Economic, social and regional sciences (ESR). The project also benefited from a grant of the Faculty of Business Administration of the University of Groningen.

\section{Appendix}

\section{Game setting Experiment I}

Two firms operate in the same market: firms I and II. Both firms can choose between two price strategies: setting a low price and setting a high price. The profits depend on the pairs of strategies chosen. In the following payoff matrix, the four possible profit combinations (in thousands of Dutch Guilders, Dfl.) are reported for Experiment I $\left(\mathrm{P}_{\mathrm{i}}\right.$ stands for the price strategy of firm $\mathrm{i}$, with $\mathrm{i}=\mathrm{I}, \mathrm{II})$.

Firm II

\begin{tabular}{llll} 
& & Low price & High price \\
\hline \multirow{2}{*}{ Firm I } & Low price & $(-30,-30)$ & $(600,-600)$ \\
& High price & $(-600,600)$ & $(300,300)$ \\
\hline
\end{tabular}


Each cell contains the possible profit combinations $\left(\mathrm{W}_{\mathrm{I}}, \mathrm{W}_{\mathrm{II}}\right)$. $\mathrm{W}_{\mathrm{I}}$ and $\mathrm{W}_{\mathrm{II}}$ are the (negative or positive) profits of firm I and firm II, respectively. The four profit combinations are the following:

(1) $\mathrm{P}_{\mathrm{I}}$ low $=\mathrm{P}_{\mathrm{II}}$ low. Both firms choose to set the same low price. The profit margins are negative. Both firms generate a loss of Dfl. 30,000.

(2) $\mathrm{P}_{\mathrm{I}}$ low $<\mathrm{P}_{\text {II }}$ high. Firm I offers a lower price than firm II. The customers of firm II prefer to buy from the 'cheaper' firm I. The profit of firm I is therefore Dfl. 600,000, and the loss of firm II amounts to Dfl. 600,000.

(3) $\mathrm{P}_{\mathrm{I}}$ high $>\mathrm{P}_{\mathrm{II}}$ low. Firm II underprices firm I. The resulting profit combination is the opposite of the second case. Firm I generates a loss of Dfl. 600,000, and firm II a profit of Dfl. 600,000 .

(4) $P_{I}$ high $=P_{I I}$ high. Both firms choose to set the same high price. The profit margins are positive. Both firms gain a profit of Dfl. 300,000.

\section{Game I}

Suppose you are Chief Executive Officer of firm I. You decide autonomously on the price strategy of your company. You have an appointment with your distributor to fix the future price strategy for your product. It is a custom in this industry that yearly contracts with distributors are drawn, in which the price level you prefer to set in each month (or round) for the coming year is stipulated in advance. It is impossible to change the terms of the contract afterwards. The Chief Executive Officer of firm II will simultaneously determine her/his price strategy with her/his distributor (another than yours) for the following twelve months. You do not know the price intentions of firm II (and vice versa). Indicate below for each round (month) which strategy you prefer ( $\mathrm{L}$ indicates low price; $\mathrm{H}$ indicates high price).

\section{Game II}

At the end of the contract, you found out that firm II has consistently chosen to set a high price in each month of the previous contracting period. Subsequently, you have to draw a new contract with your distributor for the next twelve months. Indicate again which price strategy you prefer in each month.

\section{Game III}

Your information on the past intentions and price strategy of firm II became irrelevant. The reason is that firm II has been taken over by another company, which installed a new Chief Executive Officer. The government has also decided that contracts in which prices are set for more than one month in advance are now illegal. Thus, for the next year you are only allowed to fix your price level for one month; after every month you have to decide again for the next round. Decisions are made simultaneously in each month.

You play the game for an unknown number of months (rounds). You do not know in advance how many times you will have to make a decision on your price strategy. The game can end any moment after round 8 . The probability that the game ends after round 8 equals 20 per cent. The sequence of decisions/activities you have to perform is as follows: 
(1) at the beginning of each round, the price strategies are set simultaneously and marked on the associated response sheet;

(2) subsequently, the choices of both firms are exchanged by means of pieces of paper provided by the experimenter; and

(3) finally, compute your own profit, given the strategy of the other firm.

Indicate for each month on your response sheet: (i) the strategy you prefer, (ii) the strategy of the other firm and (iii) the profit you gained. Except for the exchange of the pieces of paper after each round, no communication is allowed during the experiment.

\section{Game IV}

Repeat game III for a known number of months (rounds). More precisely, you play the game for twelve rounds (months).

\section{Game V}

In the following period of twelve months demand has increased substantially, associated with an increasing profit potential. This new situation is reflected in the following profit combinations (profits are in thousands of Dutch Guilders, Dfl.).

Firm I

\begin{tabular}{lll} 
& Firm II & \\
\cline { 2 - 2 } & Low price & High price \\
\hline Low price & $(-20,-20)$ & $(800,-400)$
\end{tabular}

High price

$(-400,800)$

$(600,600)$

Proceed as in game IV.

\section{Game setting Experiment II}

The game setting in Experiment II is exactly the same except for slight differences in the payoff structure. For the first four games the following profit (loss) combinations were used: $(-20,-20)$, $(500,-500),(-500,500),(200,200)$. In game V these combinations are: $(10,10),(700,-700)$, $(-700,700),(400,400)$.

\section{References}

Boone, C. (1992). Onderzoek naar het verband tussen de perceptie van controle van bedrijfsleiders en de strategie en de resultaten van ondernemingen in de meubelindustrie. Unpublished doctoral dissertation. University of Antwerp, Antwerp.

Boone, C., De Brabander, B., Gerits, P., \& Willemé, P. (1990). Relation of scores on Rotter's I-E scale to short-term and long-term control expectancies and fatalism. Psychological Reports, 66, 1107-1111. 
Boone, C., De Brabander, B., \& van Witteloostuijn, A. (1999a). Locus of control and strategic behaviour in a prisoner's dilemma game. Personality and Individual Differences, 27, 695-706.

Boone, C., De Brabander, B., \& van Witteloostuijn, A. (1999b). The impact of personality on behaviour in five prisoner's dilemma games. Journal of Economic Psychology, 20, 343-377.

Boone, C., \& van Witteloostuijn, A. (1999). Competitive and opportunistic behaviour in a prisoner's dilemma game: experimental evidence on the impact of culture and education. Scandinavian Journal of Management, 15, 333-350.

Cox, T. H., Lobel, S. A., \& McLeod, P. L. (1991). Effects of ethnic group cultural differences on cooperative and competitive behaviour on a group task. Academy of Management Journal, 34, 827-847.

Cronbach, L. J. (1951). Coefficient $\alpha$ and the internal structure of tests. Psychometrika, 16, 297-335.

Dawes, R. M. (1980). Social dilemmas. Annual Review of Psychology, 31, 169-193.

De Brabander, B., \& Boone, C. (1990). Sex differences in perceived locus of control. Journal of Social Psychology, 130, 271-272.

De Brabander, B., Boone, C., \& Gerits, P. (1992). Locus of control and cerebral asymmetry. Perceptual and Motor Skills, 75, 131-143.

Frank, R. H., Gilovich, T., \& Regan, D. T. (1993). Does studying economics inhibit cooperation? Journal of Economic Perspectives, 7, 159-171.

Kuhlmann, D. M., \& Marshello, A. F. (1975). Individual differences in game motivation as moderators of preprogrammed strategy effects in Prisoner's Dilemma. Journal of Personality and Social Psychology, 32, 922-931.

Lefcourt, H. M. (1982). Locus of control: current trends in theory and research (2nd ed.). Hillsdale NJ: Lawrence Erlbaum.

McGinnies, E., Nordholm, L. A., Ward, C. D., \& Bhanthumnavin, D. L. (1974). Sex differences and cultural differences in perceived locus of control among students in five countries. Journal of Consulting and Clinical Psychology, $42,451-455$.

Nunnally, J. C. (1978). Psychometric theory (2nd ed.). New York: McGraw-Hill.

Phares, E. J. (1976). Locus of control in personality. Morristown, NJ: General Learning Press.

Pruitt, D., \& Kimmel, M. (1977). Twenty years of experimental gaming: critique, synthesis, and suggestions for the future. Annual Review of Psychology, 28, 363-392.

Raiffa, H. (1982). The art and science of negotiation. Cambridge, MA: Harvard University Press.

Rapoport, A., Guyer, M., \& Gordon, D. (1976). The 2 x 2 game. Ann Arbor: University of Michigan Press.

Rasmusen, E. (1990). Games and information: an introduction to game theory (2nd ed.). Cambridge: Basil Blackwell.

Robinson, J. P., \& Shaver, P. R. (1973). Measures of social psychological attitudes. Ann Arbor, MI: University of Michigan, Survey Research Center, Institute for Social Research.

Rotter, J. B. (1966)Generalized expectancies for internal versus external control of reinforcement. Psychological Monographs: General and Applied, 80, whole number 609.

Schlenker, B. R., Helm, B., \& Tedeschi, J. T. (1973). The effects of personality and situational variables on behavioural trust. Journal of Personality and Social Psychology, 25, 419-427.

Uejio, C. K., \& Wrightsman, L. (1967). Ethnic group differences in the relationship of trusting attitudes to cooperative behaviour. Psychological Reports, 20, 3-571.

van Olffen, W. (1999). Team level locus of control and competitive team behaviour: an experimental study Unpublished doctoral dissertation, Datawyse, Maastricht.

Weiss, H. M., \& Adler, S. (1984). Personality and organizational behaviour. Research in Organizational Behaviour, 6, $1-50$. 